\title{
Effects of boron addition and intensive grinding on synthesis of anorthite ceramics
}

\author{
Sedat Kavalci ${ }^{a}$, Emre Yalamaç $^{\mathrm{b}}$, Sedat Akkurt ${ }^{\mathrm{b}, *}$ \\ ${ }^{a}$ Materials Science and Engineering Program, İzmir Institute of Technology, 35430 Izmir, Turkey \\ ${ }^{\mathrm{b}}$ Mechanical Engineering Department, Izmir Institute of Technology, 35430 İzmir, Turkey \\ Received 13 November 2006; received in revised form 8 April 2007; accepted 15 July 2007 \\ Available online 10 August 2007
}

\begin{abstract}
Anorthite ceramics were synthesized starting from mixtures prepared by using mechanochemical methods with boron oxide addition. The raw materials used in this study were Sivas Kaolin, calcined alumina/ $\mathrm{Al}(\mathrm{OH})_{3}$ and calcite. Statistical experimental design techniques (SED) were used in order to determine and analyze the more important process variables for synthesizing anorthite ceramics. Phase characterizations of synthesized powders were performed by XRD using $\mathrm{Cu} \mathrm{K} \alpha$ radiation. Microstructural characterization was performed by SEM. The results of screening experimental design clarified that the temperature was the most important process variable. Second most important process variable was grinding speed of starting mixture which was followed by additive amount and additive type. The effect of both additive use and grinding on anorthite synthesis helped decrease the synthesis temperature down to $900{ }^{\circ} \mathrm{C}$.
\end{abstract}

(C) 2007 Elsevier Ltd and Techna Group S.r.l. All rights reserved.

Keywords: A: Powders: Solid state reaction; A: Milling; Anorthite; Statistical experimental design

\section{Introduction}

Anorthite $\left(\mathrm{CaO} \cdot \mathrm{Al}_{2} \mathrm{O}_{3} \cdot 2 \mathrm{SiO}_{2}\right)$ ceramics are promising materials for substrate applications in electronics industry due to their good physical properties. Anorthite has a thermal expansion coefficient of $45 \times 10^{-7} 1 /{ }^{\circ} \mathrm{C}$ and low dielectric constant of $\varepsilon_{\mathrm{r}} \approx 6.2$ at $1 \mathrm{MHz}$. This is reasonably a good match to silicon [1]. Because of these desirable properties, anorthite ceramics have attracted attention and several studies were carried out in order to decrease the sintering and crystallization temperature below $1000{ }^{\circ} \mathrm{C}$ [2-5]. Low sintering temperature below $1000{ }^{\circ} \mathrm{C}$ is a prerequisite for substrate applications that allow the ceramic material to co-fire with conductive metals such as copper, gold and silver [3].

Synthesis of anorthite was extensively studied. Techniques for anorthite synthesis include sintering of solid mixtures of calcium carbonate, kaolinite, alumina, and aluminum hydroxide in addition to mechanochemical treatments, sol-gel process of dehydration of appropriate metal hydroxides, or

\footnotetext{
* Corresponding author. Tel.: +90 232750 6192; fax: +90 2327507890 .

E-mail addresses: sdtka@yahoo.com (S. Kavalci), emreyalamac@iyte.edu.tr (E. Yalamaç), sedatakkurt@iyte.edu.tr (S. Akkurt).
}

employing different additives in solid state sintering process such as $\mathrm{B}_{2} \mathrm{O}_{3}, \mathrm{Na}_{2} \mathrm{CO}_{3}, \mathrm{TiO}_{2}, \mathrm{CaF}_{2}$. All these methods carry their own advantages and disadvantages [1-5].

Mergen and Aslanoğlu had reported that single phase anorthite ceramic with $87 \%$ theoretical density could be obtained from heating of raw materials Groleg kaolinite (China), quartz and calcite at $950{ }^{\circ} \mathrm{C}$ by using boron oxide additons [3]. In a more recent study of Mergen et al. the effect of another boroncontaining additive, colemanite $\left(2 \mathrm{CaO} \cdot 3 \mathrm{~B}_{2} \mathrm{O}_{3} \cdot 5 \mathrm{H}_{2} \mathrm{O}\right)$, was studied. They used domestic impure kaolinite, calcite and quartz as raw materials which were relatively coarse. They concluded that the bulk density of the sintered ceramics at $1350{ }^{\circ} \mathrm{C}$ with colemanite addition reached $91.3 \%$ theoretical density. On the other hand, the batches without additive only reached $73.5 \%$ of theoretical density at the same sintering temperature and process conditions [4]. Kobayashi and Kato employed excessive grinding for controlling the particle size of calcite. The other raw materials used for anorthite synthesis was New Zealand kaolin. The mean particle size for calcite was reduced down to $1.5 \mu \mathrm{m}$. The samples were fired around $1000{ }^{\circ} \mathrm{C}$ to produce $94 \%$ theoretical density at $950{ }^{\circ} \mathrm{C}$. As a result, they stated that reduction of particle size of calcite led to an increase in the density of fired products [5]. 
Table 1

Published chemical analyses of the raw materials and additives (wt.\%)

\begin{tabular}{|c|c|c|c|c|}
\hline & Sivas Kaolin & CT3000SG Alumina (ALCOA) & Colemanite (Eti Holding) & Boric acid (Eti Holding) \\
\hline $\mathrm{Al}_{2} \mathrm{O}_{3}$ & 33.07 & 99.6 & 0.00 & 0.00 \\
\hline $\mathrm{SiO}_{2}$ & 52.86 & 0.03 & 6.5 & 0.00 \\
\hline $\mathrm{MgO}$ & 0.00 & 0.09 & 0.00 & 0.00 \\
\hline $\mathrm{Na}_{2} \mathrm{O}$ & 0.13 & 0.08 & 0.00 & 0.00 \\
\hline $\mathrm{K}_{2} \mathrm{O}$ & 0.12 & 0.00 & 0.00 & 0.00 \\
\hline $\mathrm{CaO}$ & 0.47 & 0.02 & 27 & 0.00 \\
\hline $\mathrm{Fe}_{2} \mathrm{O}_{3}$ & 0.05 & 0.02 & 0.00 & 0.00 \\
\hline $\mathrm{TiO}_{2}$ & 0.38 & 0.00 & 0.00 & 0.00 \\
\hline $\mathrm{MnO}$ & 0.10 & 0.00 & 0.00 & 0.00 \\
\hline $\mathrm{SO}_{3}$ & 0.60 & 0.00 & 0.00 & 0.00 \\
\hline $\mathrm{B}_{2} \mathrm{O}_{3}$ & 0.00 & 0.00 & 42.5 & 56.25 \\
\hline LOI & 12.22 & 0.16 & - & - \\
\hline Total & 100.00 & 100.00 & 100.0 & 100.00 \\
\hline
\end{tabular}

In this study, anorthite was synthesized by employing high speed mechanical grinding and by using boron-containing additives. According to the authors knowledge utilizing both intensive mechanical grinding and employing additives has not yet been studied. A similar approach was recently carrried out by the authors [6]. The experiments were planned by the use of statistical experimental design techniques (SED). First, Plackett-Burmann screening experimental design was employed to separate the more important factor effects. Second, ladder experiments were performed to understand the effects of alumina source and grinding speed on the success of anorthite synthesis.

\section{Experimental procedure}

\subsection{Materials}

Raw materials used for anorthite synthesis were Sivas Kaolin $\left(\mathrm{Al}_{2} \mathrm{O}_{3} \cdot 2 \mathrm{SiO}_{2} \cdot 2 \mathrm{H}_{2} \mathrm{O}\right)(<38 \mu \mathrm{m})$ [7], reagent grade calcium carbonate $\left(\mathrm{CaCO}_{3}\right)$ (Sigma, ALDRICH) reagent grade aluminium hydroxide (Gibbsite) $\left(\mathrm{Al}(\mathrm{OH})_{3}\right)$ (MERCK) or calcined reactive alumina $\left(\mathrm{Al}_{2} \mathrm{O}_{3}\right)$ (ALCOA CT3000SG). Boric acid $\left(\mathrm{H}_{3} \mathrm{BO}_{3}\right)$ and colemanite $\left(2 \mathrm{CaO} \cdot 3 \mathrm{~B}_{2} \mathrm{O}_{3} \cdot 5 \mathrm{H}_{2} \mathrm{O}\right)$ were used as additive for decreasing the synthesis temperature of anorthite [8]. Boron-containing additives were selected in this study due to the low melting point $\left(450{ }^{\circ} \mathrm{C}\right)$ of $\mathrm{B}_{2} \mathrm{O}_{3}$ [9] and partly due to less negative effect on insulating characteristics than the other sintering aids [3]. The chemical analyses of the raw materials used in anorthite synthesis is given in Table 1.

\subsection{Method}

The raw materials were mixed in proper amounts to obtain a 1:1:2 stoichiometric anorthite mixture. The amounts of raw materials and additives are tabulated in Table 2. In the first set of experiments only calcined alumina was used as a source of $\mathrm{Al}_{2} \mathrm{O}_{3}$. The effect of the use of aluminium hydroxide instead of calcined alumina was also investigated during following experiments. Powder mixtures were wet milled (in $60 \mathrm{ml}$ deionized water) in planetary mono mill (Fritsch Pulverisette
6). The mill pot and grinding media (10 $\mathrm{mm}$ diameter) were made of tungsten carbide. The grinding speed and duration were varied in the range of $100-500 \mathrm{rpm}$ and $15-75 \mathrm{~min}$, respectively. The ground slurry was spread on tray and dried at $103{ }^{\circ} \mathrm{C}$ in electric oven. The agglomerates of particles were crushed with porcelain mortar and pestle to obtain fine powder. The powder was pressed uniaxially in universal hydraulic press (Yıldız Hidrolik San. Tic., 2001 Model) at $100 \mathrm{MPa}$ in stainless steel die $(\varnothing 15.2 \mathrm{~mm})$ to form pellets which were sintered in a globar benchtop kiln (Alser Teknik A. Protherm PLF 160/5) at a temperature range of $900-1100{ }^{\circ} \mathrm{C}$ with soaking time of $1-5 \mathrm{~h}$ with constant heating rate of $10{ }^{\circ} \mathrm{C} / \mathrm{min}$. The kiln was allowed to cool by itself in air. The heated pellets were half-crushed for $\mathrm{X}$-ray diffraction (XRD) analysis.

\subsection{Statistical experimental design}

Plackett-Burmann screening design is applied in which the more important factor effects are identified in the early stages of the project [10]. This approach allows the experimenter to evaluate large number of experimental factors with few experiments and without the need to replicate experiments to draw statistically valid conclusions $[11,12]$. The price paid for reduction of experimental runs is the inability to identify high order interactions between the parameters.

Table 2

The amounts of raw materials and additives for mixtures

\begin{tabular}{lll}
\hline Raw material & Chemical formula & Amount $(\mathrm{g})$ \\
\hline Sivas Kaolin & $\mathrm{Al}_{2} \mathrm{O}_{3} \cdot 2 \mathrm{SiO}_{2} \cdot 2 \mathrm{H}_{2} \mathrm{O}$ & $15 \mathrm{~g}$ \\
Calcium carbonate & $\mathrm{CaCO}_{3}$ & $6.48 \mathrm{~g}$ \\
Alumina & $\mathrm{Al}_{2} \mathrm{O}_{3}$ & $1.76 \mathrm{~g}$ \\
Aluminium hydroxide & $\mathrm{Al}(\mathrm{OH})_{3}$ & $2.692 \mathrm{~g}$ \\
Colemanite & $2 \mathrm{CaO} .3 \mathrm{~B}_{2} \mathrm{O}_{3} \cdot 5 \mathrm{H}_{2} \mathrm{O}$ & $1 \mathrm{wt} \%, 0.540 \mathrm{~g}$ \\
& & $3 \mathrm{wt} \%, 1.620 \mathrm{~g}$ \\
& & $5 \mathrm{wt} \%, 2.760 \mathrm{~g}$ \\
Boric acid & $\mathrm{H}_{3} \mathrm{BO}_{3}$ & $1 \mathrm{wt} \%, 0.412 \mathrm{~g}$ \\
& & $3 \mathrm{wt} \%, 1.236 \mathrm{~g}$ \\
& & 5 wt. $\%, 2.060 \mathrm{~g}$ \\
\hline
\end{tabular}


Table 3

The factors for Plackett-Burmann screening design

\begin{tabular}{|c|c|c|c|c|}
\hline Factor & $k$ & High level (+) & Low level $(-)$ & Type of variable \\
\hline Additive type & A & Boric acid & Colemanite & Discrete \\
\hline Additive amount & B & 5 wt. $\%$ & $1 \mathrm{wt} . \%$ & Continuous \\
\hline Heating temperature & $\mathrm{C}$ & $1100{ }^{\circ} \mathrm{C}$ & $900{ }^{\circ} \mathrm{C}$ & Continuous \\
\hline Soaking time & $\mathrm{D}$ & $5 \mathrm{~h}$ & $1 \mathrm{~h}$ & Continuous \\
\hline Grinding time & $\mathrm{E}$ & $60 \mathrm{~min}$ & $15 \min$ & Continuous \\
\hline Grinding speed & $\mathrm{F}$ & $500 \mathrm{rpm}$ & $100 \mathrm{rpm}$ & Continuous \\
\hline
\end{tabular}

Table 4

Experiments designed via Plackett-Burmann approach [11]

\begin{tabular}{|c|c|c|c|c|c|c|c|c|c|c|c|c|}
\hline \multirow[t]{2}{*}{ Run order } & \multirow[t]{2}{*}{ Mixtures } & \multicolumn{6}{|c|}{ Variables $^{\mathrm{a}}$} & \multicolumn{5}{|c|}{ Unassigned columns $^{\mathrm{a}}$} \\
\hline & & A & B & $\mathrm{C}$ & $\mathrm{D}$ & $\mathrm{E}$ & $\mathrm{F}$ & G & $\mathrm{H}$ & $\mathrm{J}$ & K & $\mathrm{L}$ \\
\hline 5 & S9 & + & + & - & + & + & + & - & - & - & + & - \\
\hline 7 & $\mathrm{~S} 12$ & + & - & + & + & + & - & - & - & + & - & + \\
\hline 11 & $\mathrm{~S} 10$ & - & + & + & + & - & - & - & + & - & + & + \\
\hline 9 & S5 & + & + & + & - & - & - & + & - & + & + & - \\
\hline 4 & $\mathrm{~S} 1$ & + & + & - & - & - & + & - & + & + & - & + \\
\hline 1 & S11 & + & - & - & - & + & - & + & + & - & + & + \\
\hline 2 & S4 & - & - & - & + & - & + & + & - & + & + & + \\
\hline 12 & S6 & - & - & + & - & + & + & - & + & + & + & - \\
\hline 3 & S8 & - & + & - & + & + & - & + & + & + & - & - \\
\hline 8 & S3 & + & - & + & + & - & + & + & + & - & - & - \\
\hline 10 & S7 & - & + & + & - & + & + & + & - & - & - & + \\
\hline 6 & $\mathrm{~S} 2$ & - & - & - & - & - & - & - & - & - & - & - \\
\hline
\end{tabular}

${ }^{\text {a }}$ Factors.

In this study, we had five continuous variables; additive amount $(B)$, heating temperature $(C)$, soaking time $(D)$, grinding time $(E)$, grinding speed $(F)$ and one discrete variable of additive type $(A)$. High and low levels for these variables are shown in Table 3. The designed set of experiments (PlackettBurmann design) with 12 runs is shown in Table 4.

XRD analysis with $\mathrm{Cu} \mathrm{K} \alpha$ radiation and wavelength of $\lambda=1.54 \mathrm{~A}$, was used to detect the present phases of the heated mixtures (Philips X'pert Pro, XRD). The response variable for statistical analyses of amount of anorthite phase was the peak height of the $\left(\begin{array}{lll}0 & 0 & 4\end{array}\right)$ peak positioned at $28.03^{\circ}$ (see, e.g. JCPDS card: 41-1486). The morphology and particle size of the mixtures were observed by scanning electron microscope (Philips XL-30S FEG, SEM).

\section{Results and discussion}

\subsection{Results of Plackett-Burmann screening experiments}

The screening experiments were done under the conditions listed in Table 4 for the factors listed in Table 3. The other experimental conditions were fixed for all samples. As an example, heating rate was fixed to $10^{\circ} \mathrm{C} / \mathrm{min}$. Experimental conditions of tests done in this study are tabulated in Table 5.

XRD patterns for screening experiments are shown in Figs. 1 and 2 for samples containing boron oxide and colemanite, respectively. The main phase detected in samples that were fired at $1100{ }^{\circ} \mathrm{C}$ was anorthite with a small amount of corundum phase such as in sample $S 6$. Samples heated at $900{ }^{\circ} \mathrm{C}$, however, also contained other phases like gehlenite, quartz, and calcium borate in addition to the anorthite and corundum. In samples $S 11$ and $S 2$ the anorthite phase was not detected. The main phase in these samples was corundum with minor phases of gehlenite, calcium borate, and quartz.

Table 5

Experimental conditions of tests done in this study

\begin{tabular}{llrrrrl}
\hline Experiment no. & Factors & & & & & \\
\cline { 2 - 6 } & A & B & \multicolumn{1}{c}{ C } & D & E & F \\
\hline S1 & Boric acid & 5 & 900 & 1 & 15 & 500 \\
S2 & Colemanite & 1 & 900 & 1 & 15 & 100 \\
S3 & Boric acid & 1 & 1100 & 5 & 15 & 500 \\
S4 & Colemanite & 1 & 900 & 5 & 15 & 500 \\
S5 & Boric acid & 5 & 1100 & 1 & 15 & 100 \\
S6 & Colemanite & 1 & 1100 & 1 & 60 & 500 \\
S7 & Colemanite & 5 & 1100 & 1 & 60 & 500 \\
S8 & Colemanite & 5 & 900 & 5 & 60 & 100 \\
S9 & Boric acid & 5 & 900 & 5 & 60 & 500 \\
S10 & Colemanite & 5 & 1100 & 5 & 15 & 100 \\
S11 & Boric acid & 1 & 900 & 1 & 60 & 100 \\
S12 & Boric acid & 1 & 1100 & 5 & 60 & 100 \\
B100 & Boric acid & 1 & 900 & 1 & 60 & 100 \\
B200 & Boric acid & 1 & 900 & 1 & 60 & 200 \\
B300 & Boric acid & 1 & 900 & 1 & 60 & 300 \\
B400 & Boric acid & 1 & 900 & 1 & 60 & 400 \\
B500 & Boric acid & 1 & 900 & 1 & 60 & 500 \\
A1 & Boric acid & 3 & 900 & 1 & 75 & 500 \\
A2 & Boric acid & 3 & 900 & 1 & 75 & 500 \\
A15 & Boric acid & 3 & 900 & 1 & 15 & 500 \\
A45 & Boric acid & 3 & 900 & 1 & 45 & 500 \\
A90 & Boric acid & 3 & 900 & 1 & 90 & 500 \\
\hline
\end{tabular}




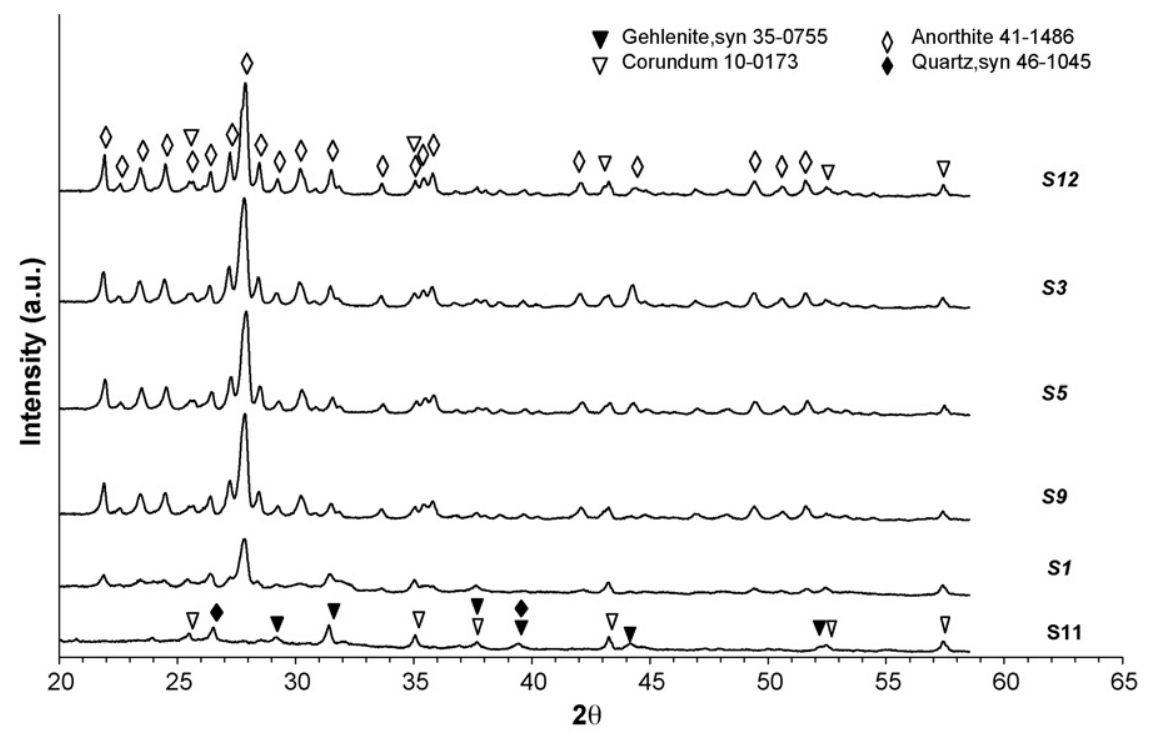

Fig. 1. XRD patterns of the samples containing boric acid as additive.

The response parameter for Plackett-Burmann screening design was taken as the height of the $(004)$ peak positioned at $28.03^{\circ}$ and they are tabulated in Table 6 . The response was taken as zero for batches in which anorthite was not detected. The maximum response of 1456 was observed in the $S 6$ batch.

To find the main factors statistical computations were done by hand and results are shown in Table 6 according to the method proposed by Harris and Lautenberger [11] and previously employed by Leigh and Towe [12]. Critical minimum difference [MIN] is calculated as shown in Eq. (1):

$S_{\mathrm{FE}}=\sqrt{\frac{1}{q}\left(\mathrm{UFE}_{1}^{2}+\mathrm{UFE}_{2}^{2}+\cdots+\mathrm{UFE}_{q}^{2}\right)} \quad[\mathrm{MIN}]=t S_{\mathrm{FE}}$ where $q$ (number of unassigned factor effects) $=n-k-1$, $n=$ number of runs $(n=12$ for 12 run Plackett-Burmann design), $k=$ number of factors $(k=6$ because six factors were studied), UFE $=$ unassigned factor effect, $t=t_{\mathrm{dof}, \alpha}($ dof $=5$ because there were five unassigned factor effects, $\alpha=$ confidence level).

Critical minimum differences [MIN] were calculated by multiplying the different $t$-values for different confidence levels at 5 dof with the $S_{\mathrm{FE}}$ value. The factor effects that have greater absolute value than this value are considered to be significant factor effects. At the $95 \%$ confidence level, heating temperature $(C)$, grinding speed $(F)$, additive amount $(B)$ and soak time (D) were significant factors in decreasing order of importance (see Table 6). Heating temperature $(C)$ had 820 units of factor effect while grinding speed $(F)$ had 436 units of factor effect both

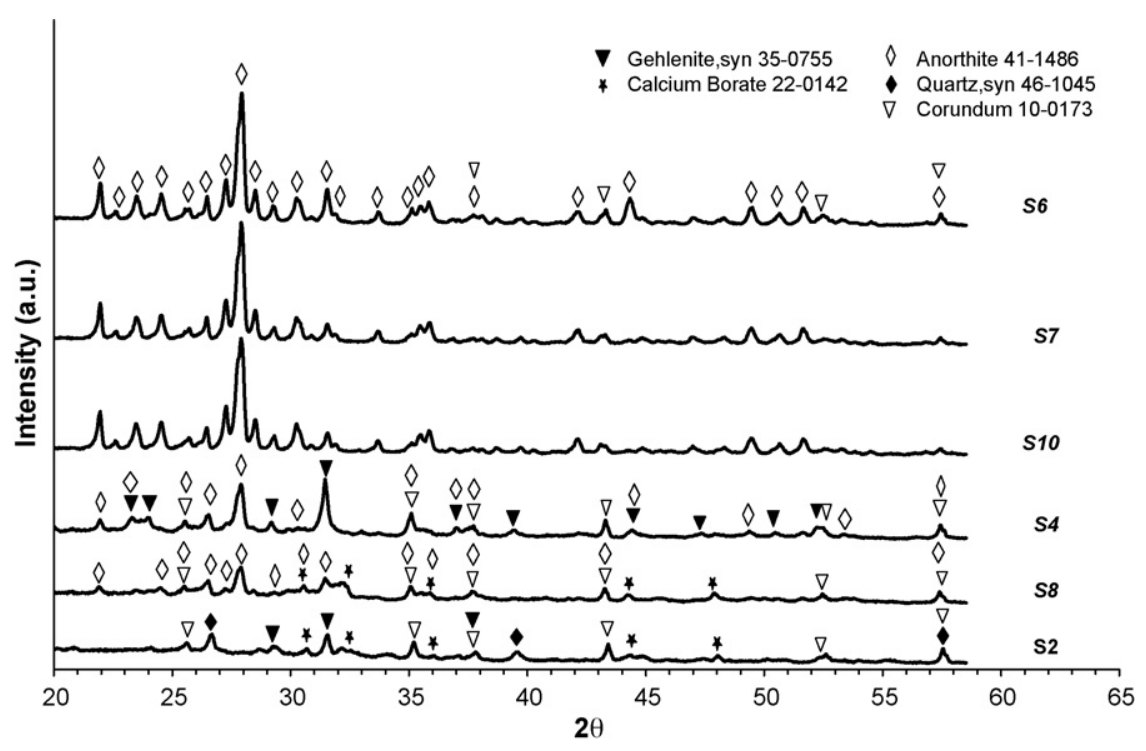

Fig. 2. XRD patterns of the samples containing colemanite as additive. 


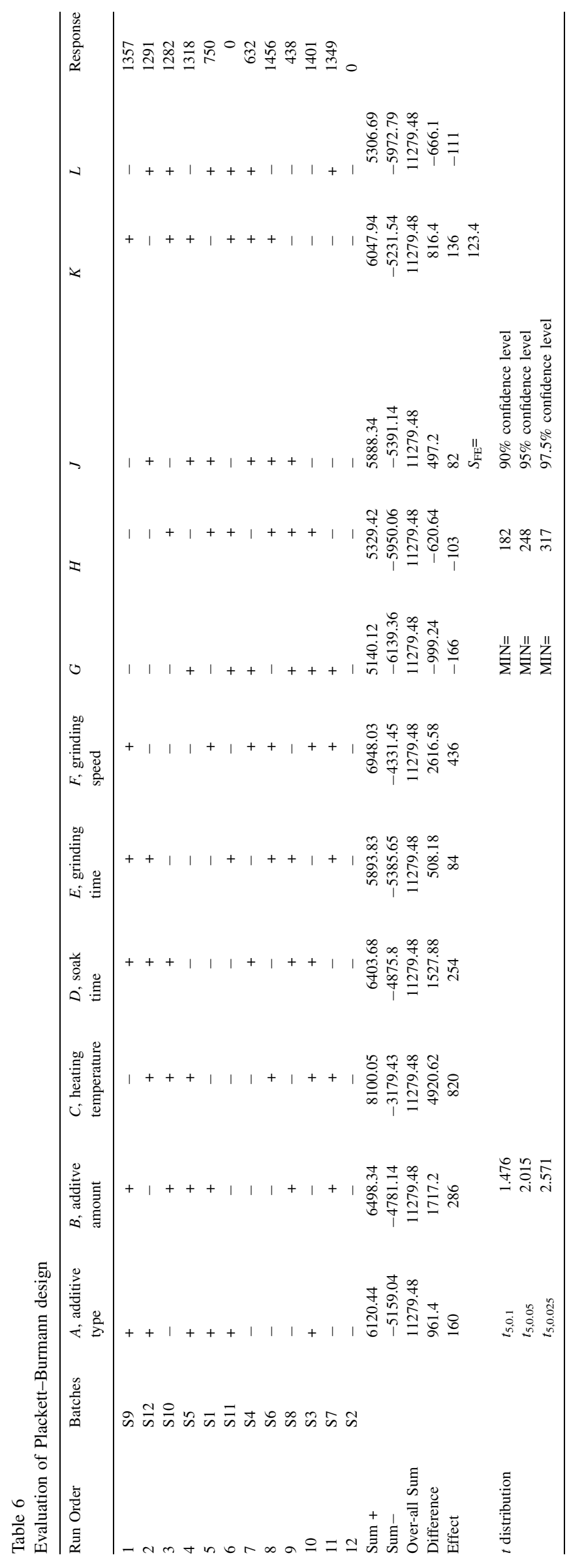

being larger than the critical MIN value of 317 for $97.5 \%$ confidence.

\subsection{Effect of heating temperature and grinding speed on anorthite synthesis}

Having identified the more important factor effects by the screening experimental design methodology, a separate set of experiments were conducted to further understand the effects of heating temperature $(C)$ and grinding speed $(F)$ on anorthite synthesis. This time a ladder experiment methodology was applied. That means the factor levels were tested at increasing levels. For example, the grinding speed was tested at 100, 200, 300,400 and $500 \mathrm{rpm}$ while heating temperature was tested at 800,900 and $1100{ }^{\circ} \mathrm{C}$. The samples that were run at $900{ }^{\circ} \mathrm{C}$ are coded B100-B500 as shown in Table 5. The results are given in Fig. 3 for the experiments at $900{ }^{\circ} \mathrm{C}$. As can be seen from Fig. 3 anorthite synthesis was improved significantly when the grinding speed was raised from 100 to $200 \mathrm{rpm}$. Further increases in the grinding speed did not raise the degree of anorthite synthesis much. The results for 800 and $1100{ }^{\circ} \mathrm{C}$ are not given here for the sake of brevity [13]. There was no significant improvement in the degree of anorthite synthesis by increasing the grinding speed at $800{ }^{\circ} \mathrm{C}$. At $1100{ }^{\circ} \mathrm{C}$, however, anorthite was successfully synthesized regardless of the degree of grinding speed.

\subsection{Effect of alumina source on anorthite synthesis}

In this section the effect of alumina source is investigated. The mixtures containing $3 \mathrm{wt} . \%$ boric acid were ground at $500 \mathrm{rpm}$ for $75 \mathrm{~min}$. The ground mixtures were then compacted and fired at $900{ }^{\circ} \mathrm{C}$ for $1 \mathrm{~h}$. These two samples were identical and the only difference between them was the source of alumina. First batch (A1) was prepared with $\mathrm{Al}_{2} \mathrm{O}_{3}$ and the second (A2) was prepared with $\mathrm{Al}(\mathrm{OH})_{3}$. The XRD results are given in Fig. 4. Anorthite and the small amount of corundum phase were detected in both samples. As can be seen from the figure the sample that was prepared with $\mathrm{Al}(\mathrm{OH})_{3}$ produced a slightly more intense anorthite peak at $28.03^{\circ} 2 \theta$. Three more experiments were done at grinding durations of 15,45 and $90 \mathrm{~min}$. Anorthite peak intensity was found to moderately increase when the grinding duration was raised from 15 to 45 min (Fig. 5).

\subsection{Microstructural analyses (SEM)}

In order to investigate the microstructural status of the synthesized pellets, SEM analyses were performed on polished cross-sections of specimens. Back-scattered electron images of selected samples are presented in Fig. 6. The sample heated at higher temperature of $1100{ }^{\circ} \mathrm{C}$ was found to be denser. Phase distribution of the anorthite was found to be quite uniform in all areas of microstructure. The structure, however, had densities of around $76 \%$ of the theoretical density. More work needs to be done to increase the density of the product. 


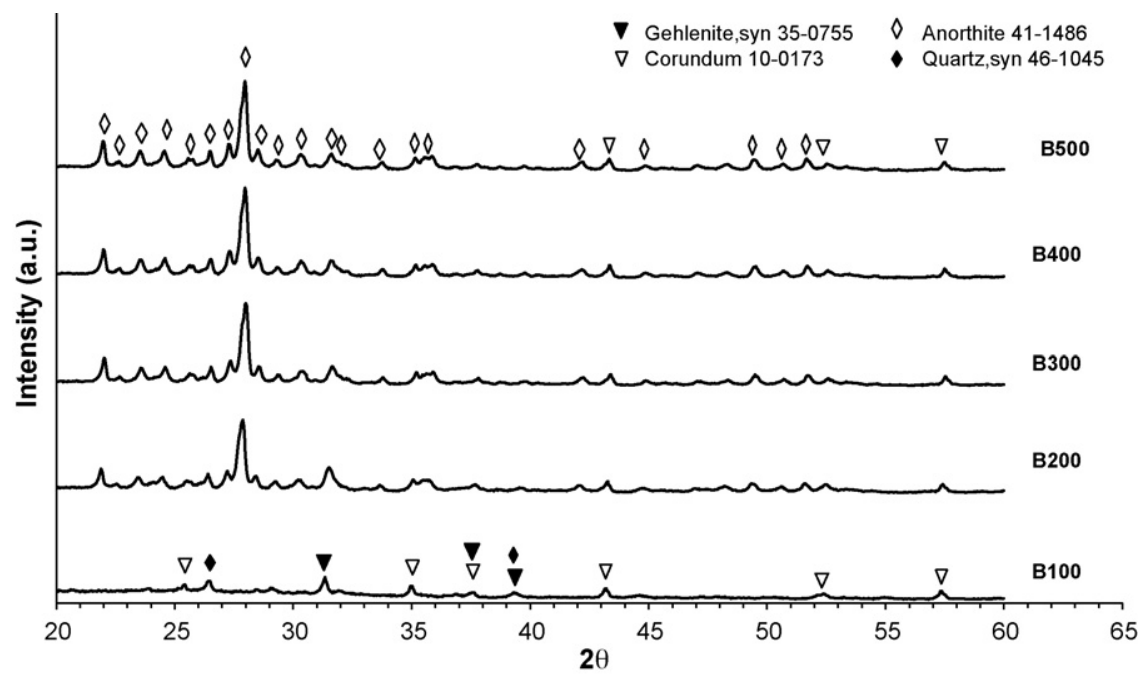

Fig. 3. The XRD patterns of samples were fired at $900{ }^{\circ} \mathrm{C}$ and ground at different speeds.

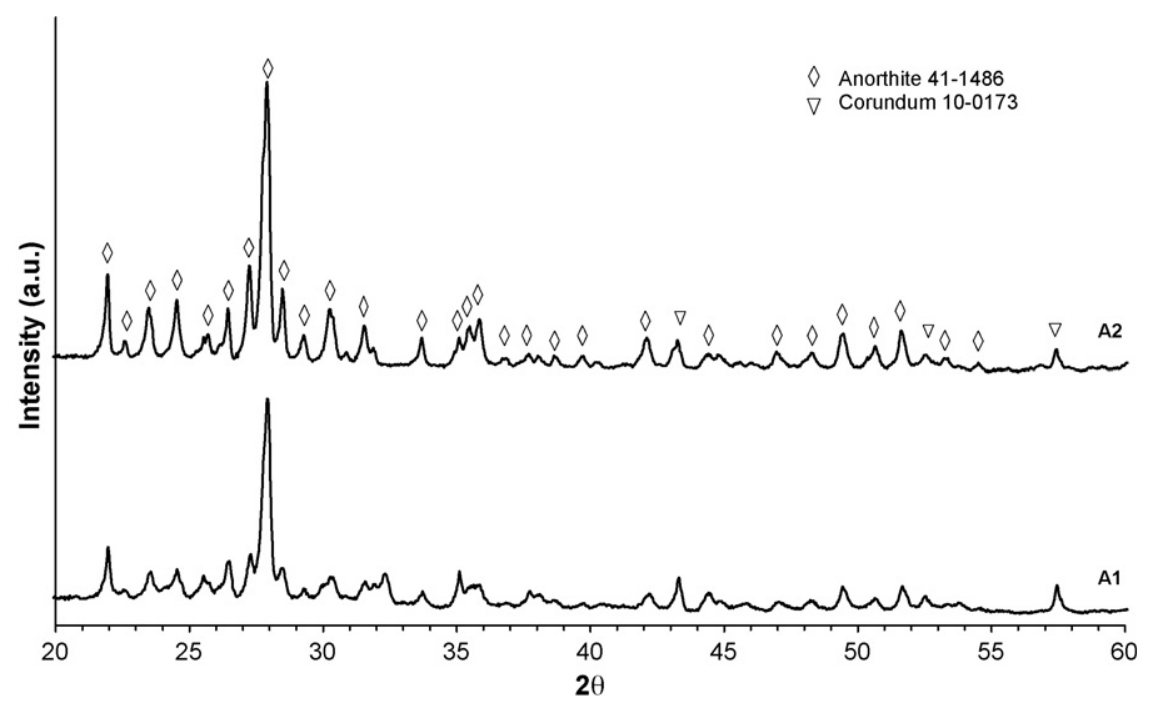

Fig. 4. The XRD patterns of samples have different $\mathrm{Al}_{2} \mathrm{O}_{3}$ sources.

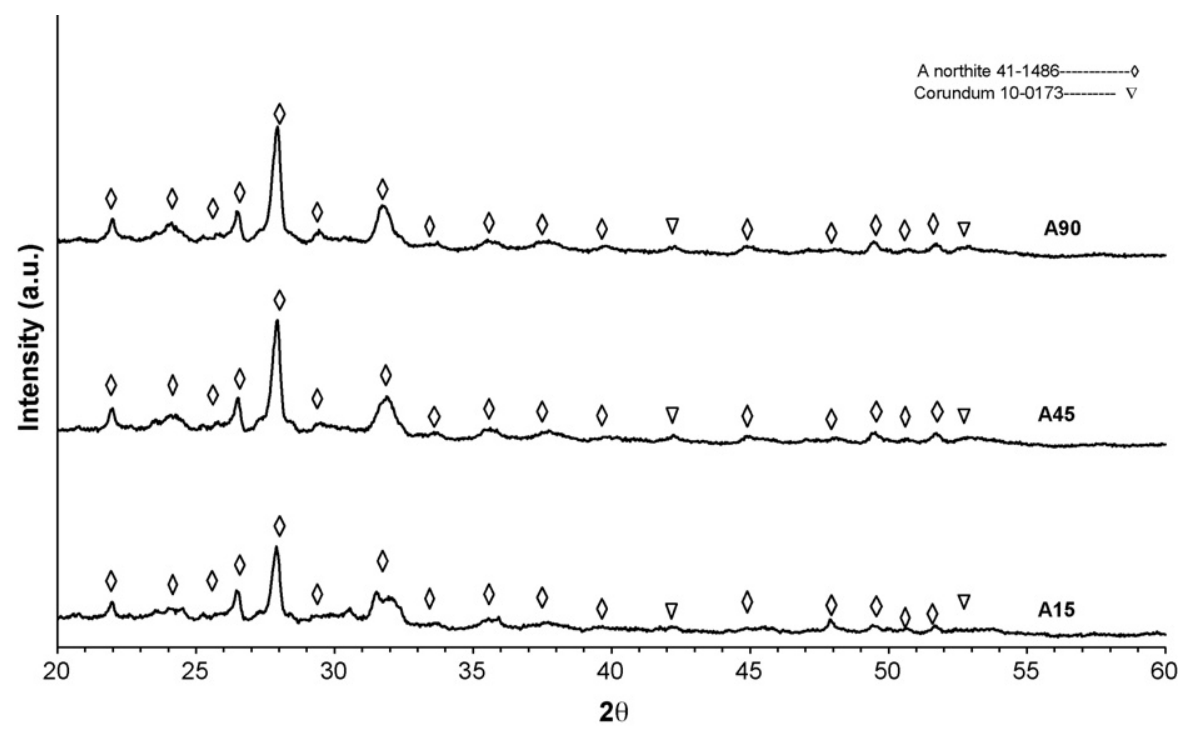

Fig. 5. The XRD patterns of samples containing $\mathrm{Al}(\mathrm{OH})_{3}$ that were ground for varying durations. 

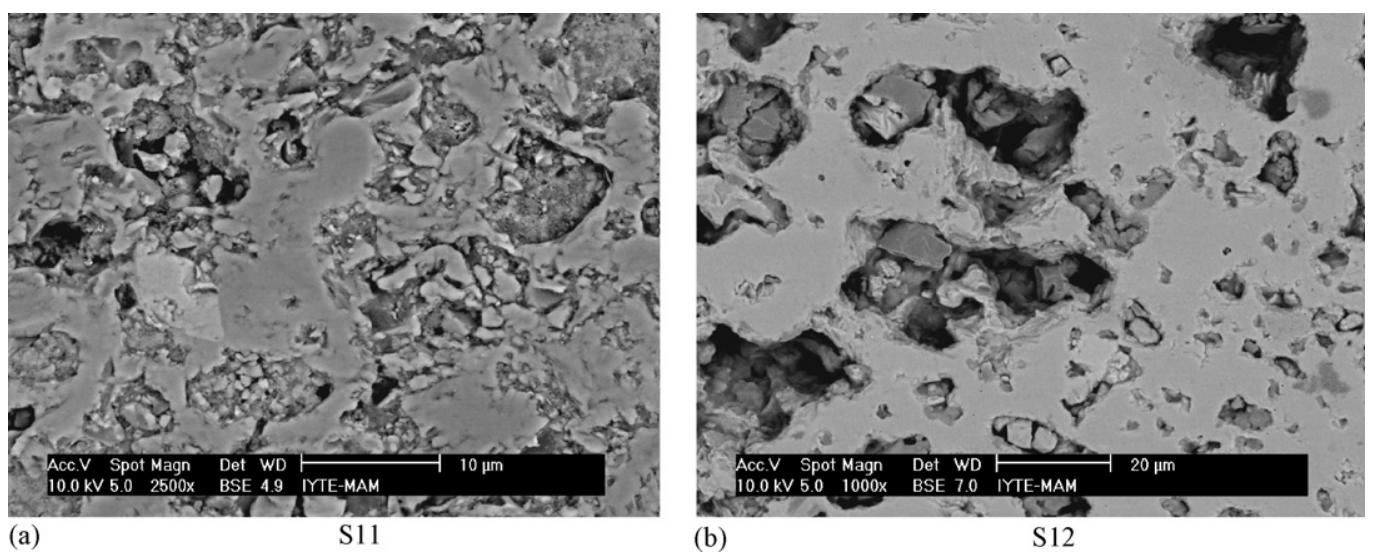

Fig. 6. SEM micrographs of specimens heated at different temperatures (S11: $\left.900{ }^{\circ} \mathrm{C}, \mathrm{S} 12: 1100{ }^{\circ} \mathrm{C}\right)$ and soak times $(\mathrm{S} 11: 1 \mathrm{~h}, \mathrm{~S} 12: 5 \mathrm{~h})$.

\section{Conclusions}

In this study, the effects of heating temperature, soaking time, amount and type of additives and mechanochemical treatment on synthesis of anorthite ceramics were investigated. The use of statistical techniques to identify the more significant parameters was successfully demonstrated. As a result of the screening experiments, the effects of heating temperature, grinding speed, additive amount and soak time were found to be more significant. In the final set of experiments, the effects of different alumina sources were investigated with ladder experiments. The use of $\mathrm{Al}(\mathrm{OH})_{3}$ instead of calcined alumina as a source of $\mathrm{Al}_{2} \mathrm{O}_{3}$ slightly improved anorthite formation.

Anorthite formation temperature was decreased down to $900{ }^{\circ} \mathrm{C}$ by the combined effect of additive usage and high speed grinding. The positive effect of high speed milling helped reduce the anorthite formation temperature. Microstructures of the heated pellets were also observed using SEM to find out that the structure was porous. Anorthite phase was successfully produced as a result of this study. More study is needed to produce more dense products for use as a ceramic.

\section{References}

[1] R.A. Gdula, Anorthite ceramic dielectrics, Ceram. Int. 50 (6) (1971) 555557.
[2] S. Lee, G. Kim, Characteristics and densification behavior of anorthite powder synthesized by a solution process employing a polymer carrier, J. Ceram. Process. Res. 3 (3) (2002) 136-140.

[3] A. Mergen, Z. Aslanoğlu, Low-temperature fabrication of anorthite ceramics from kaolinite and calcium carbonate with boron oxide addition, Ceram. Int. 29 (5) (2003) 667-670.

[4] A. Mergen, T.S. Kayed, M. Bilen, A.F. Qasrawi, M. Gürü, Production of anorthite from kaolinite and $\mathrm{CaCO}_{3}$ via colemanite, Key Eng. Mater. 264268 (4) (2004) 1475-1478.

[5] Y. Kobayashi, E. Kato, Low temperature fabrication of anorthite ceramics, J. Am. Ceram. Soc. 77 (3) (1994) 833-834.

[6] E. Yalamaç, S. Akkurt, Additive and intensive grinding effects on the synthesis of cordierite, Ceram. Int. 32 (2006) 1115-1122.

[7] M.S. Kırıkoğlu, A. Sümer, S.G. Özkan, G. Özden, Investigation of some physical and chemical properties with respect to processing of Kaolin samples from Sivas deposits in Turkey, Key Eng. Mater. 264-268 (3) (2004) 1423-1426.

[8] ETİ Mining Inc., Product Information, Boric Acid and Ground Colemanite, İstanbul, 2005.

[9] C.G. Bergeron, S.H. Risbud, Introduction to Phase Equilibria in Ceramics, American Ceramic Society, Westerville, Ohio, 1984.

[10] D.C. Montgomery, Design and Analysis of Experiments, 6th ed., John Wiley \& Sons Inc., USA, 2005.

[11] H. Harris, W. Lautenberger, Strategy of Experimentation, E.I. Dupont de Nemours \& Co. Inc. Short Course Notes, 1976.

[12] H.D. Leigh, C.A. Towe, Use of a screening experimental design to develop a high $\mathrm{Al}_{2} \mathrm{O}_{3}$ casting slip, Am. Ceram. Soc. Bull. 66 (5) (1987) 786-789.

[13] S. Kavalc1, The use of Boron-Containing Additives for Synthesis of Anorthite Ceramic Powders, M.Sc. Thesis, 2007, İzmir Institute of Technology, İzmir. 